\title{
ELASTIC INTRAMEDULLARY NAILING OF METACARPAL FRACTURES
}

\author{
Ch. V. Murali Krishna ${ }^{1}$, P. Ashok Kumar², P. Rambabu³, K. Srinivasarao ${ }^{4}$, K. Vamsi Krishna 5 , P. Ravi Chandra ${ }^{6}$, P. Vamsi Krishna ${ }^{7}$, \\ P. Ravi ${ }^{8}$
}

${ }^{1}$ Assistant Professor, Department of Orthopaedics, King George Hospital, Andhra Medical College, Visakhapatnam, Andhra Pradesh. 2 Professor I/c, Department of Orthopaedics, King George Hospital, Andhra Medical College, Visakhapatnam, Andhra Pradesh. ${ }^{3}$ Assistant Professor, Department of Orthopaedics, King George Hospital, Andhra Medical College, Visakhapatnam, Andhra Pradesh. ${ }_{4}^{4}$ Assistant Professor, Department of Orthopaedics, King George Hospital, Andhra Medical College, Visakhapatnam, Andhra Pradesh. ${ }_{5}^{5}$ Assistant Professor, Department of Orthopaedics, King George Hospital, Andhra Medical College, Visakhapatnam, Andhra Pradesh. 6 Junior Resident, Department of Orthopaedics, King George Hospital, Andhra Medical College, Visakhapatnam, Andhra Pradesh. ${ }^{7}$ Junior Resident, Department of Orthopaedics, King George Hospital, Andhra Medical College, Visakhapatnam, Andhra Pradesh. 8Junior Resident, Department of Orthopaedics, King George Hospital, Andhra Medical College, Visakhapatnam, Andhra Pradesh.

ABSTRACT

\section{BACKGROUND}

AIM

The goal of treatment in metacarpal fractures is to restore the normal function of the hand. ${ }^{1}$ The main aim of this study is to evaluate the clinical and radiological outcomes of intramedullary nailing with titanium elastic nails.

\section{MATERIALS AND METHODS}

Eighteen patients with 21 metacarpal fractures who attended the orthopaedic OPD at King George Hospital, Visakhapatnam, from September 2014 to August 2015 were studied. All the nails were passed antegradely.

\section{RESULTS}

Functional evaluation was done based on DASH score at three months after fixation of fractures.

\section{CONCLUSION}

Fractures of metacarpal bones are one of the common fractures involving short long bones. Treatment with elastic nails is more encouraging with good functional results.

\section{KEYWORDS}

TENS, Elastic Nails, Metacarpals.

HOW TO CITE THIS ARTICLE: Krishna CVM, Kumar PA, Rambabu P, et al. Elastic intramedullary nailing of metacarpal fractures. J. Evolution Med. Dent. Sci. 2016;5(21):1086-1089, DOI: 10.14260/jemds/2016/251

\section{INTRODUCTION}

Fractures of metacarpals account for nearly $36 \%$ of all hand fractures. ${ }^{2}$ while many metacarpal fractures can be treated with non-surgical means, unstable metacarpal fractures which are subject to malrotation, displacement, shortening and angulation require reduction and stable fixation. ${ }^{2}$ Antegrade intramedullary pinning was shown to produce better functional outcomes than percutaneous transverse pinning or miniplate fixation. ${ }^{3}$ Cadaveric studies showed decreased hand function with metacarpal shortening beyond $5 \mathrm{~mm}$ and angulation beyond 30 degrees. ${ }^{4}$ Any rotation is poorly tolerated and needs correction. ${ }^{4}$ Elastic nails provide three point intramedullary fixation providing adequate stability and promote early motion. 4

Uncorrected bone deformity and stiffness resulting from metacarpal shaft fracture can produce significant functional and cosmetic deformity. ${ }^{5}$ Intramedullary fixation of

Financial or Other, Competing Interest: None.

Submission 10-11-2015, Peer Review 11-11-2015,

Acceptance 19-11-2015, Published 11-03-2016.

Corresponding Author:

Dr. P. Ashok Kumar,

\# B-98, Dayal Nagar,

Visakhapatnam-530043,

Andhra Pradesh.

E-mail: ashok_ortho59@rediffmail.com

DOI: $10.14260 /$ jemds/2015/251 metacarpal shaft fractures has been advocated to simplify the surgical treatment of these common injuries and minimize the complications associated with more extensive procedures. ${ }^{5}$

The principles of treatment include restoration of articular anatomy, stable fixation of the fractures, elimination of angular or rotational deformity and rapid restoration of mobility and function. ${ }^{6}$ It provides distinct advantages over other methods, because it is minimally invasive with minimal soft tissue dissection, stability of fixation and enhancing bone healing by preventing distraction at the fracture site. This is particularly a great option for patients presenting with multiple metacarpal fractures. ${ }^{2}$

This method can be offered as an effective and safe alternative in the treatment of closed displaced fractures of the $2^{\text {nd }}$ to $5^{\text {th }}$ metacarpals without significant complications. ${ }^{7}$

\section{Mode of Injury}

- RTA.

- Assault.

- Fall.

- Dog bite.

\section{MATERIAL AND METHODS}

\section{Inclusion Criteria}

Displaced fractures of the shaft and neck of metacarpals are included in this study. 


\section{Exclusion Criteria}

1. All fractures of the phalanges.

2. Fractures involving the articular surface.

3. Grossly comminuted shaft fractures.

4 Badly crushed injuries.

\section{SURGICAL TECHNIQUE}

\section{Selection of Implant}

The size of the nail depends on the size of the medullary canal. The narrowest part of the medullary canal is taken into consideration. It is not uniform in all the bones. Usually one nail is sufficient. Multiple nails can be inserted if the fracture is unstable or for those who have wide medullary canal. Smaller diameter nails, i.e. $0.8 \mathrm{~mm}$ will bend while negotiating. Larger diameter nails are difficult to manoeuvre and chances of splintering the bone. Ideal size would be 1.5 and $2 \mathrm{~mm}$ nails.

\section{Entry Point}

In our series, all the nails were passed from the base of the metacarpals, i.e. antegradely.

\section{PROCEDURE}

The patient is given local anaesthesia with sedation/wrist block. After preparation under antibiotic cover and fluoroscopic control, site of entry wound is confirmed under Carm. A stab incision is given over the base of the fractured bone. Blunt dissection is done up to the dorsal cortex to prevent damage to the extensor tendons. Entry point is made with K-wire or a drill bit of larger diameter than the nail. Then the TENS is held with T-handle and negotiated into the entry point.

The fracture is reduced. Nail is passed across the fracture site into the distal fragment. The nail is advanced up to the subchondral bone. Manual rotation of the nail can assist in final reduction. Final position of the reduction is checked under $\mathrm{C}$-arm and the nail is cut after bending; average time taken for surgery is $15-20 \mathrm{~min}$.

\section{Post-0p}

Physiotherapy was started immediately in post-operative period. Both active and passive movements of the metacarpophalangeal and interphalangeal joints were advised. Regular dressings were done and exposed nail tip is taken care of. Nails were removed at 6-8 weeks postop.

\section{Complications}

Nail back out

-Nil

Infection superficial

$-01$

Malunion

-nil

Stiffness

Penetration of nail through

the metacarpal head

Delayed union/non-union

\section{RESULTS}

All patients were followed for average period of 12 to 16 weeks. All fractures healed without rotational or angulational deformities. All patients have full ROM of

metacarpo- phalangeal and interphalangeal joints except 02 patients. Patients are satisfied functionally and cosmetically. All the patients were back to their previous job/work. The mean DASH score was 2.1-3.1 points.

\begin{tabular}{|c|l|}
\hline Males & 17 \\
\hline Females & 01 \\
\hline Single bone fracture & 15 \\
\hline Multiple bone fracture & 03 \\
\hline Metacarpal fractures & 21 \\
\hline Compound & 01 \\
\hline Simple & 17 \\
\hline
\end{tabular}

\section{CONCLUSION}

Elastic stable intramedullary nailing of the metacarpals is safe, minimal invasive and technically easy option in displaced fractures that warrant surgical intervention achieving excellent long-term results. ${ }^{8}$

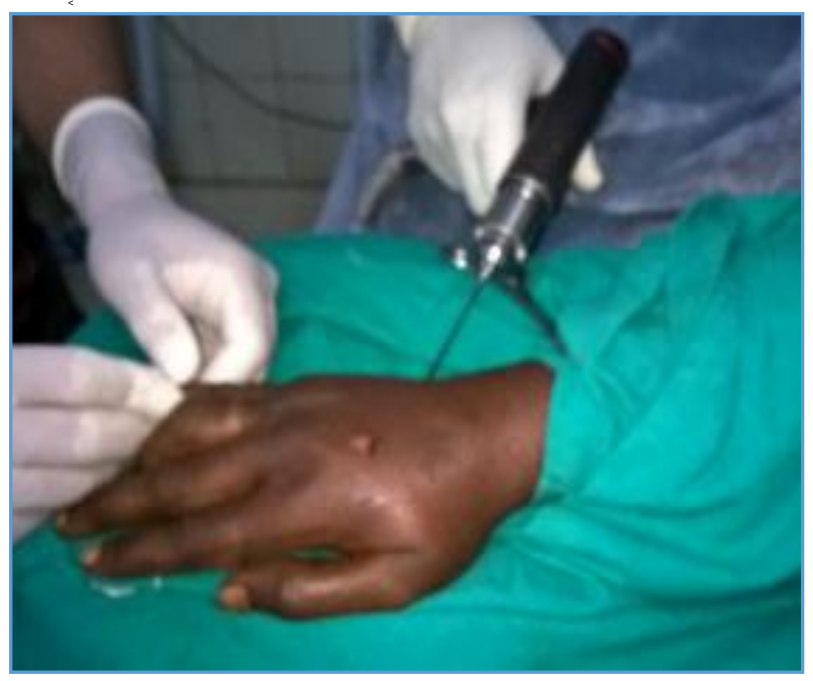

Fig. 1: Entry Point

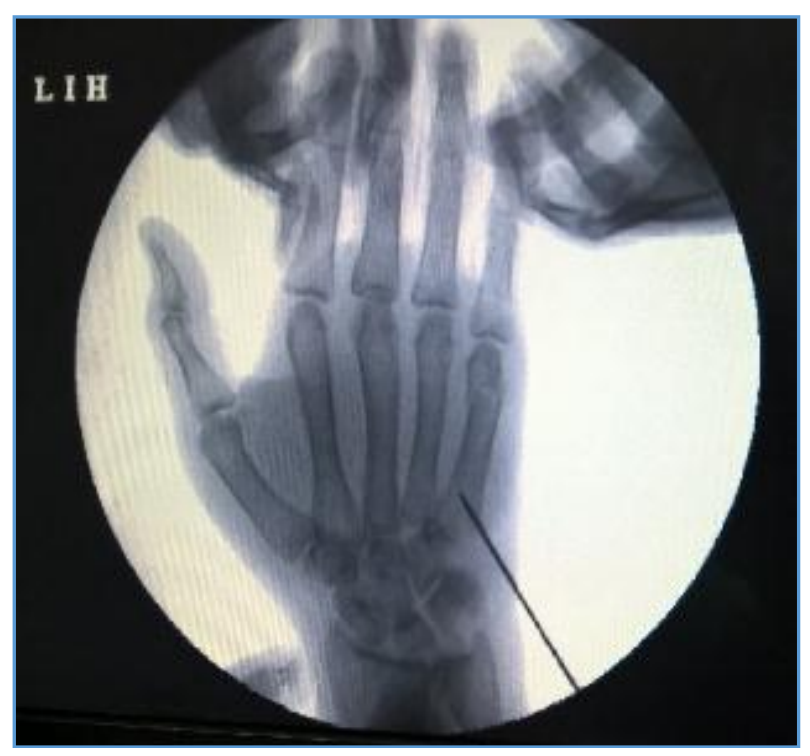

Fig. 2: Entry Point under C. Arm 


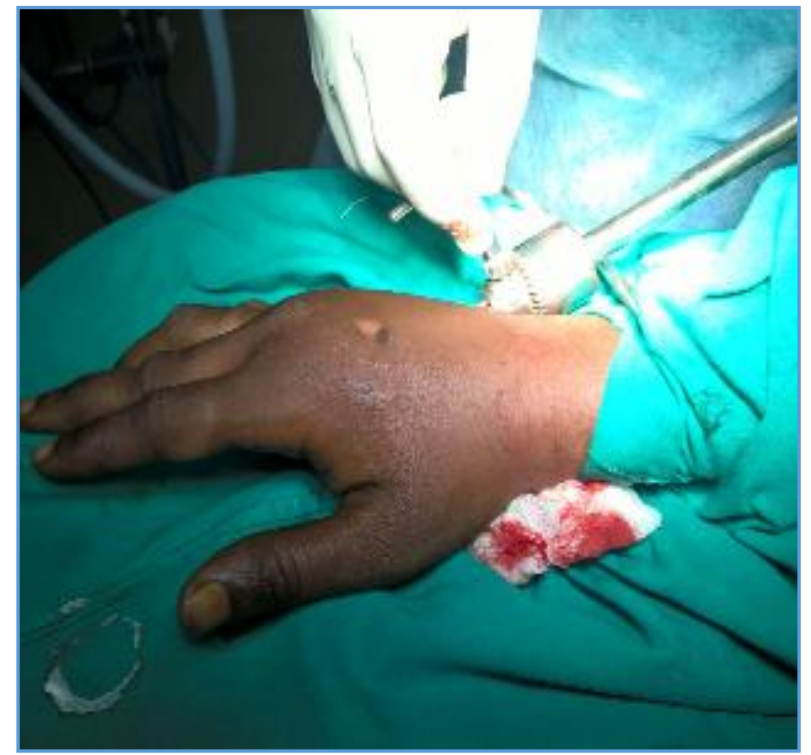

Fig. 3: Tens with T Handle

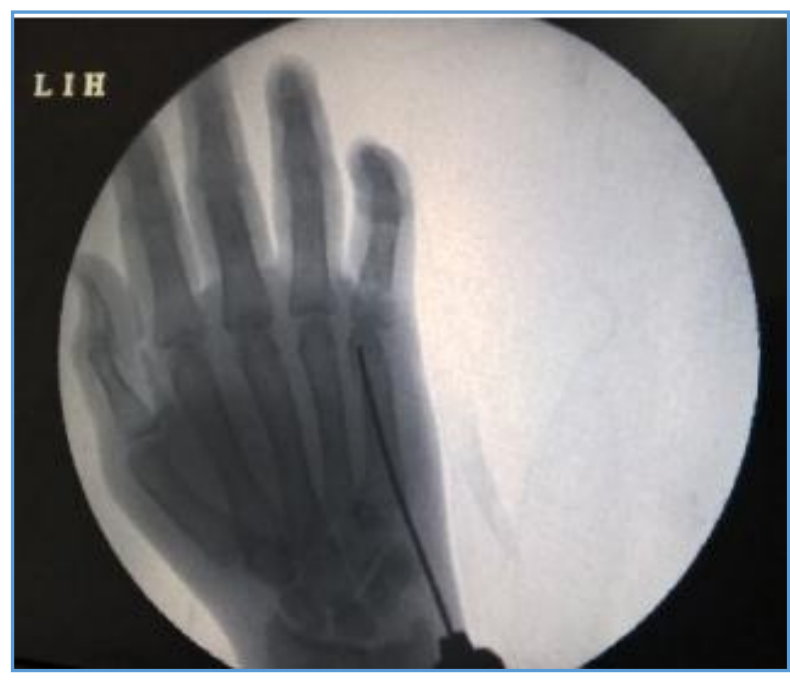

Fig. 4: Final Picture

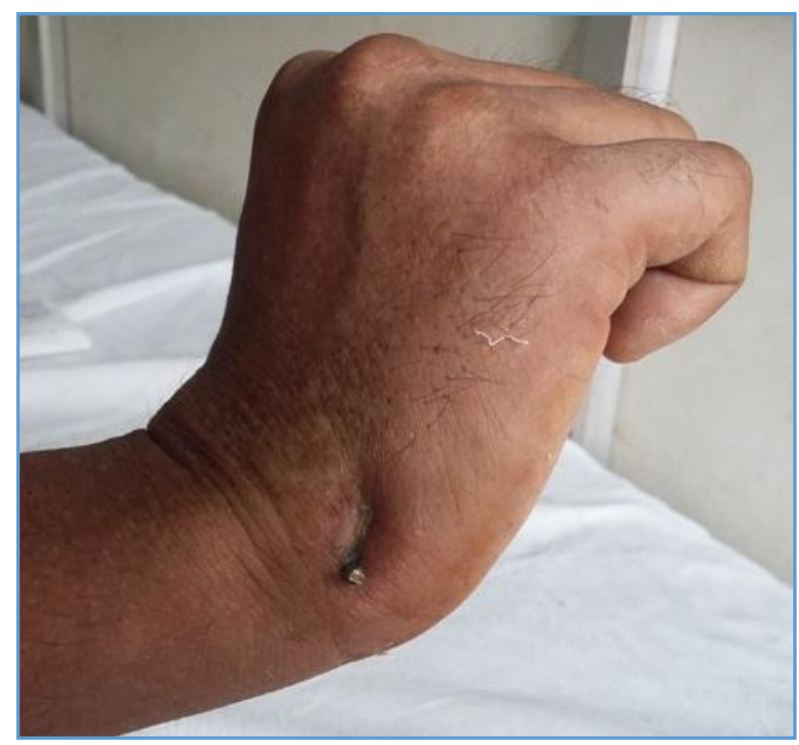

Fig. 5: ROM with Nail in situ

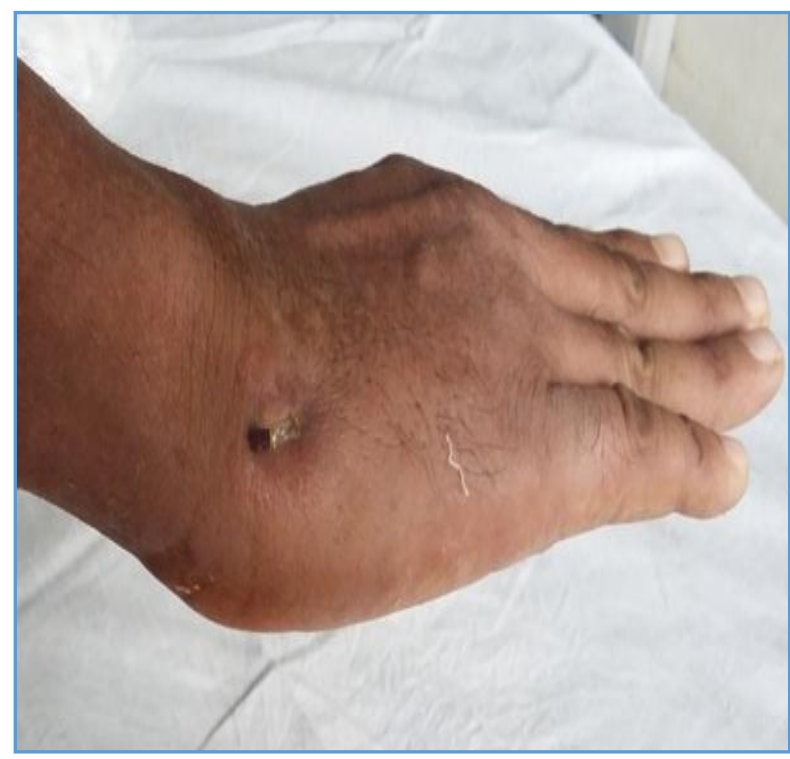

Fig. 6: ROM with Nail in situ

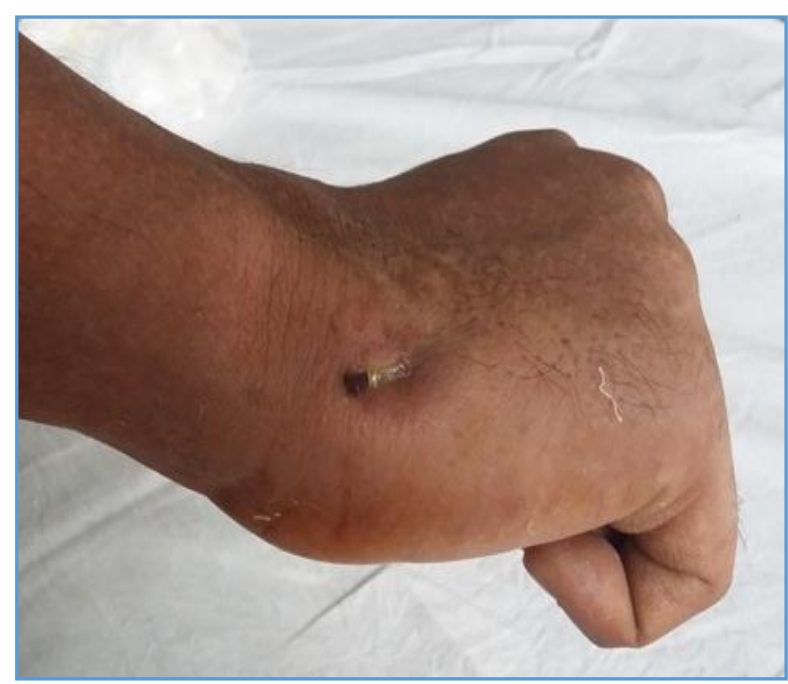

Fig. 7: ROM with Nail in situ

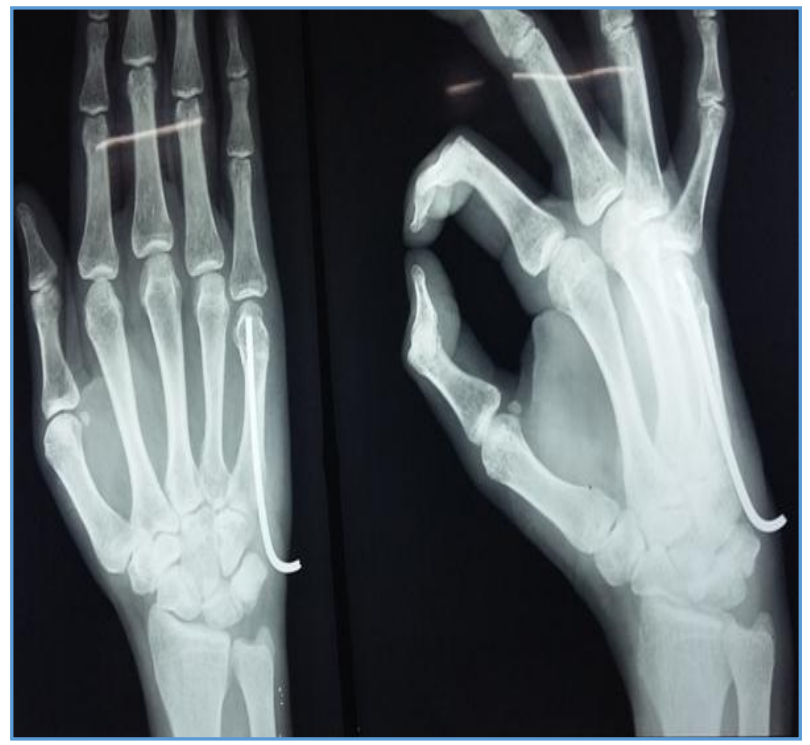

Fig. 8: Postop X-ray 


\section{REFERENCES}

1. Müller $\mathrm{MC}^{1}$, Welle $\mathrm{K}$, Windemuth $\mathrm{M}$, et al. Elastic titanium nails for minimally invasive intramedullary splinting of metacarpal fractures. [Article in German]. Z Orthop Unfall. 2013 Oct;151(5):525-31. doi: 10.1055/s-00331350875. Epub 2013 Oct 15.

2. Ather Mirza, MD; Justin B Mirza, DO; Ather Mirza, Smithtown, NY. Unstable Metacarpal Fractures Treated with Intramedullary Nail Fixation. AAHS January 21-24, 2015.

3. Kim JK, Kim DJ - Antegrade intramedullary nailing versus retrograde intramedullary pinning for displaced $5^{\text {th }}$ metacarpal fractures. Clinical Orthopaedics Related Research 2015 May;473(5):1747-54.

doi.10.1007/s11999-014-4079-7. Epub 2014 Dec 11.

4. Riazuddin Mohammed, 1 Mohamed Z Farook ${ }^{2}$ and Kevin Newman. ${ }^{3}$ Percutaneous elastic intramedullary nailing of metacarpal fractures: Surgical technique and clinical results study. Journal of Orthopaedic Surgery and Research 2011;6:37.
5. Orbay $\mathrm{J}^{1}$. Intramedullary nailing of metacarpal shaft fractures. Tech Hand Up Extrem Surg. 2005 Jun;9(2):6973.

6. Boussakri $\mathrm{H}^{1}$, Elidrissi $\mathrm{M}^{1}$, Azarkane $\mathrm{M}^{1}$, et al. Fractures of the neck of the fifth metacarpal bone, treated by percutaneous intramedullary nailing: surgical technique, radiological and clinical results study (28 cases). Pan African Medical Journal 2014 Jul 4;18:187. doi: 10.11604/pamj.2014.18.187.3347.

7. Kaiser $\mathrm{MM}^{1}$, Tafazzoli $\mathrm{K}$, Theilen TM, et al. Intramedullary nailing for metacarpal 2-5 fractures. J Pediatr Orthop B 2009 Nov;18(6):296-301.

doi: 10.1097/BPB.0b013e32832f5abb.

8. Lieber J1, Härter B, Schmid E, et al. Elastic stable intramedullary nailing (ESIN) of pediatric metacarpal fractures: experiences with 66 cases. Eur J Pediatric Surg. 2012 Aug;22(4):305-310. doi: 10.1055/s-0032-1313339. Epub 2012 May 30. 